thương tích và bệnh lý khác chiếm 54,5\%, trong đó cấp cứu y tế chủ yếu là tai nạn thương tích chiếm $34,4 \%$ và nguyên nhân cấp cứu do bệnh lý khác chiếm 20,2\%.

\section{TÀI LIÊU THAM KHẢO}

1. Hà Ânh (2017). Tiếp nhận và Theo dõi bênh nhân cấp cứu nặng. s.l. : Hội ningị Quốc tế về Y̛ học cấp cứu nắm 2017, chủ biển.

2. Nguyễn Thị Giang, Nguyễn Bích Diệp, Nguyễn Đình Khuề (2016). Thực trang tai nan lao động và môt số yếu tố liên quan của ngư dẩn đánh bắt hải sản xa bờ thị xã Cửa Lò, tỉnh Nghệ An năm 2014. s.l. : Tap chí Y học dự phòng, Tập XXVI, số 11 (184) 2016,

3. Trân Đăng Khoa (2013). Thực trạng và kết quả một số giải pháp can thiệp tăng cương tiếp cân sử dụng dịch vụ khám, chưa bệnh y tế công lập tại huyện Như Xuân 2009-2011. Thanh Hóa : Luận án Tiến sĩ Y tế Công cộng, đại học Y tế công cộng.

4. Lê Hồng Minh (2011). Ṅghiên cứu điều kiện lao động và sức khỏe nghề nghiệp của ngư dân đánh bắt hải sản xa bờ ở một sổ tỉnh phía Nam Việt Nam. Hà Nôii : Luân án tiến sĩ, Học viện Quân y.

5. Nguyến Văn Tẩm (2016). Thực trạng tai nan thương tích của ngư dân đánh bắt xa bờ và thuyền viên khu vực phía Bắc năm 2014-2016. không biết chủ biên : Kỷ yếu công trình nghiên cứu khoa học y học bjển.

6. Nguyê̂n Văn Tâm, Trân Thị Quỳnh Chi, Nguyễn Quang Hùng (2021). Thực trạng công tác chăm sóc sức khỏe cho ngư dân làm viếc trên tàu bắt hải sản tại một số ngư trường Vịnh Bắc Bộ, duyên hải miền Trung, Vịnh Thái Lan từ năm 2015-2017.s1.: tập 31, số 12021

7. C. Matheson, S. Morrison, et al (2001). The health of fishermen in the catching sector of the fishing industry: a gap analysis. s.l. : Occupational Medicine. 51(5), p. 305-311.

8. Olaf C. C. Jensen, Gudrun Petursdottir, et al (2014). A review of fatal accident incidence rate trends in fishing. s.l. : International maritime health. $65(2)$, p. 47-52.

\title{
KẾT QUẢ PHẪU THUÂ̂T NộI SOI LÔNG NGỰC ĐIỀU TRI TRÀN KHÍ MÀNG PHỔI TỰ PHÁT TIÊN PHÁT TẠI BỆNH VIỆN HỮU NGHI VIỆT ĐỨC
}

\author{
Nguyễn Đức Thái ${ }^{1}$, Phạm Hữu Lư $^{2}$, Trần Bình Giang ${ }^{2}$
}

\section{TÓM TẮT}

Đăt vấn đề: Tràn khí màng phổi tự phát tiên phát là bệnh lý thường xảy ra ở người trẻ với tỉ lệ tái phát nhất định. Hiện nay, phẫu thuật nội soi lổng ngực được sử dụng trong điêu trị tràn khí màng phổi tự phát tiên phát thướng quy tại các trung tâm phấu thuật lồng ngực. Phương pháp: Nghiên cứu mô tả cắt ngang; Kết quả nghiên cứu ghi nhận ở các biến số: Tuổi, giới tính; Thời gian phâ̂u thuật; Tỷ lệ gây dính màng phổi ; Thời gian hậu phẫu... Số liệu được ghi nhận vào mấu bệnh án nghiên cứu cho từng bệnh nhân và xử lý bằng chương trình SPSS 20.0. Kết quả: Từ tháng 01/2018 đến 04/2021 có 38 bệnh nhân được phẫu thuật nội soi lồng ngực điều trị tràn khí màng phổi tự phát tiên phát. Cắt đốt hoặc/và khâu bóng khí bằng Stapler hoặc khâu tay kèm có/không gây dính màng phổi bằng trà nhám màng phổi vùng đỉnh và gây dính chủ động bằng Betadin đặc. Thời gian phẫu thuật trung bình là 63,16 phút. Ngày nằm hậu phẫu trung bình 5,16 ngày. Không có biến chứng cững như tử vong. Theo dõi từ 1 tháng đến 24 tháng, không có trường hợp nào tái phát. Kết luận: Phẫu thuật nội soi lồng ngực là phương pháp ngoại khoa hiệu quả trong điều trị tràn khí màng phổi tự phát tiên phát với ưu

\footnotetext{
${ }^{1}$ Bệnh viện Phổi Hà Nội

${ }^{2}$ Bệnh viện Hữu nghi Việt Đức

Chịu trách nhiệm chính: Phạm Hữu Lư

Email: phamhuulu@hmu.edu.vn

Ngày nhận bài: 11.5.2021

Ngày phản biện khoa học: 28.6.2021

Ngày duyệt bài: 7.7.2021
}

điểm giảm đau sau mổ, giảm thời gian nằm viện và giảm tî lệ tái phát.

\section{SUMMARY \\ RESULTS OF VIDEO-ASSISTED \\ THORACOSCOPIC SURGERY FOR THE TREATMENT OF SPONTANEOUS PRIMARY SPONTANEOUS PREUMOTHORAX AT VIET DUC UNIVERSITY HOSPITAL}

Background: Primary spontaneous pneumothorax is a common disease in young people with a recurrence rate. Currently, video-assisted thoracoscopic surgery is used in the routine treatment of primary spontaneous pneumothorax in thoracic surgery centers. Methods: Cross-sectional descriptive study; The research results were recorded in the following variables: age, sex; operative time; rate of pleural adhesions; post-operative time... The data were recorded in the research medical record for each patient and processed by the SPSS 20.0. Results: From January 2018 to April 2021, 38 patients underwent video-assisted thoracoscopic surgery for primary spontaneous pneumothorax. Bleb ablation and/and blebectomy - suture with Stapler or manual suturing with/without pleural adhesions with apical pleural sanding and active adhesion with the pure Betadin. The average operative time was 63.16 minutes. The average postoperative day was 5.16 days. There were no complications nor death. Followup from 1 month to 24 months, no cases of recurrence. Conclusion: Thoracoscopic surgery is an effective surgical method in the treatment of primary spontaneous pneumothorax with the advantages of 
reducing postoperative pain, reducing hospital stay and reducing the recurrence rate.

\section{I. ĐẶT VẤN ĐỀ}

Tràn khí màng phổi (TKMP) là tình trạng xuất hiện khí một cách bất thường trong khoang màng phổi (KMP) ${ }^{1}$. Tràn khí màng phổi tự phát tiên phát (TKMPTPTP) là tình trạng tràn khí thường xảy ra ở bệnh nhân trẻ, khỏe mạnh không có bệnh lý phổi. Tần suất TKMPTPTP là 4-9/100.000 dân số, tỷ lệ nam với nữ từ 4-6/12. Trước đây điều trị bằng đặt dẫn lưu, tỷ lệ thành công khoảng 70$80 \%{ }^{3}$, số còn lại phải phẫu thuật là những trường hợp rò khí kéo dài hoặc phổi không nở hết sau đặt ống dẫn lưu, những trường hợp này phải mở ngực để giải quyết chỗ rò khí: khâu hoặc cắt bóng khí. Đây là phẫu thuật lớn, xâm lấn nhiều và có một số nhược điểm nhất định. Ngày nay với sự phát triển của kỹ thuật nội soi lồng ngực và những dụng cụ chuyên dụng, phẫu thuật nội soi lồng ngực (PTNSLN) hiện là một phưởng pháp điều trị có hiệu quả với các bệnh lý lồng ngực trong đó có TKMPTPTP. Tại trung tâm Tim mạch và Lồng ngực - Bệnh viện hữu nghị Việt Đức chúng tôi đã tiến hành PTNSLN thường quy mang lại nhiều ưu điểm cho người bệnh. Vì vậy, chúng tôi tiến hành nghiên cứu này nhằm đánh giá kết quả điều trị của phương pháp này trong thời gian gần đây.

\section{II. ĐỐI TƯỢNG VÀ PHƯƠNG PHÁP NGHIÊN CỨU}

Phương pháp nghiên cứu: Nghiên cứu mô tả cắt ngang, bao gồm hồi cứu và tiến cứu

Đối tượng nghiên cứu: Tiêu chuẩn lựa chọn: Bệnh nhân TKMPTPTP được điều trị bằng PTNSLN được chọn vào mẫu nghiên cứu với tiêu chí: TKMPTPTP; không phân biệt tuổi, giới tính; có đầy đủ hồ sơ bệnh án theo quy định. Tiêu chuẩn loại trừ; Bệnh nhân có bệnh lý tại phổi như: lao phổi, bụi phổi, COPD, ung thư phổi... trong tiền sử hoặc mới phát hiện trong quá trình điêu trị; TKMP do can thiệp của nhân viên y tế; Bệnh nhân TKMP không có chỉ định can thiệp: do tổn thương phổi nặng, do rối loạn đông máu nặng, toàn thân không đảm bảo gây mê...; Bệnh nhân không đồng ý tham gia nghiên cứu; Bệnh nhân không có đủ hồ sơ bệnh án theo quy định

Các biến số dự kiến: Kết quả nghiên cứu ghi nhận ở các biến số: Tuổi, giới tính; Thời gian phẫu thuật; Tỷ lệ gây dính màng phổi; Thời gian hậu phẫu...

Xử lý số liệu: Số liệu được ghi nhận vào mẫu bệnh án nghiên cứu cho từng bệnh nhân và xử lý bằng chương trình SPSS 20.0; Sử dụng phép kiểm định $T$ - student để so sánh hai số trung bình, $X 2$ để so sánh hai tỷ lệ giữa lô nghiên cứu và các tác giả khác

\section{KẾT QUẢ NGHIÊN CỨU}

Từ tháng 01/2018 đến 04/2021, tại Bệnh viện hữu nghị Việt Đức đã PTNSLN cho 38 trường hợp TKMPTPTP với tỷ lê là nam chiếm 78,95\% và $21,05 \%$ là nữ. Tuổi thấp nhất là 16 ; cao nhất là 72 tuổi. Trung bình 36,32 \pm 16,197 tuổi

Về lâm sàng, chủ yếu là tức (đau) ngực (47,4\%). Tức ngực kèm khó thở cũng chiếm tỷ lệ cao $(31,6 \%)$. Triệu chứng ho gặp ở ít các trường hợp, chủ yếu là ho khan, ho ít

Bảng 1: Tỷ lệ bên phổi tràn khí

\begin{tabular}{|c|c|c|}
\hline Phối tràn khí & Số lượng & Tỷ lệ \% \\
\hline Hai bên & 1 & 2.6 \\
\cline { 2 - 3 } $\begin{array}{c}\text { Phổi phải } \\
\text { Phổi trái }\end{array}$ & 20 & 52.6 \\
\cline { 2 - 3 } Tổng & 17 & 44.8 \\
\cline { 2 - 3 } & 38 & 100.0 \\
\hline
\end{tabular}

Nhận xét: Các bệnh nhân vào viện đa phần có TKMP một bên, có 1 trường hợp TKMP hai bên cùng một lúc

Bảng 2: Mức độ TKMP trên phim $X$ quang ngức

\begin{tabular}{|c|c|c|}
\hline Mức độ tràn khí & Tân số & Tỷ lệ \% \\
\hline it & 11 & 28.9 \\
\cline { 2 - 3 } nhiều & 22 & 57.9 \\
\cline { 2 - 3 } trung bình & 5 & 13.2 \\
\cline { 2 - 3 } Tổng & $\mathbf{3 8}$ & $\mathbf{1 0 0 . 0}$ \\
\hline
\end{tabular}

Nhận xét: Các bênh nhân khi vào viện đều được chụp phim Xquang ngực, đa phần các bênh nhẩn có mức độ tràn khí nhiều 22/38 trường hợp $(57,9 \%)$

Bảng 3: Bóng kén khí trên cắt lớp vi tính (CLVT) lồng ngực

\begin{tabular}{|c|c|c|}
\hline Bóng kén trên CLVT & Tân số & Tỷ lệ \%o \\
\hline Có bóng kén & 23 & 60.5 \\
\cline { 2 - 3 } Không có bóng kén & 15 & 39.5 \\
\cline { 2 - 3 } Tổng & $\mathbf{3 8}$ & $\mathbf{1 0 0 . 0}$ \\
\hline
\end{tabular}

Nhận xét: $100 \%$ các bệnh nhân vào viện được chụp CLVT lồng ngực và tỷ lệ cao phát hiện bóng, kén khí trên CLVT lî̀ng ngực

Bảng 4: Tôn thương bóng, kén khí trong mổ và xử trí

\begin{tabular}{||c|c|c|c|c|c|}
\hline \multirow{2}{*}{ Tổn thương bóng kén trong mổ } & \multicolumn{3}{|c|}{ Cách Xứ trí tốn thương } & \multirow{2}{*}{ Tổng } \\
\cline { 3 - 6 } & \multirow{2}{*}{ Đốt đơn thuân } & $\begin{array}{c}\text { Căt/ khâu đơn } \\
\text { thuân }\end{array}$ & $\begin{array}{c}\text { Căt/ khâu } \\
\text { và đốt }\end{array}$ & \\
\hline \multirow{2}{*}{ Bóng kén rải rác } & Số lượng & 1 & 6 & 3 & 10 \\
\cline { 2 - 6 } & $\%$ & $10.0 \%$ & $60.0 \%$ & $30.0 \%$ & $100.0 \%$ \\
\hline
\end{tabular}


TAP CHÍ Y HỌC VIẸT NAM TẬP 504 - THÁNG 7 - SÓ 1 - 2021

\begin{tabular}{||c|c|c|c|c|c|}
\hline \multirow{2}{*}{ Bóng kén thùy trên } & Số lượng & 0 & 22 & 4 & 26 \\
\cline { 2 - 6 } & $\%$ & $0.0 \%$ & $84.6 \%$ & $15.4 \%$ & $100.0 \%$ \\
\hline \multirow{2}{*}{ Không phát hiện bóng kén } & Số lượng & 0 & 2 & 0 & 2 \\
\cline { 2 - 6 } & $\%$ & $0.0 \%$ & $100.0 \%$ & $0.0 \%$ & $100.0 \%$ \\
\hline \multirow{2}{*}{ Tổng } & Số lượng & 1 & 30 & 7 & 38 \\
\cline { 2 - 6 } & $\%$ & $2.6 \%$ & $78.9 \%$ & $18.4 \%$ & $100.0 \%$ \\
\hline
\end{tabular}

Nhận xét: Đa phần các trường hợp có tốn thương phát hiện bóng kén trong mố được xử lý cắt/khẩu bằng Stapler hoặc khâu tay bằng chỉ prolen $4 / 0$

Bảng 5: Phương pháp phẫu thuật Phương pháp phâu thuật Tân số Tỷ lệ \%

Nội soi toàn bô

Nội soi hỗ trợ (VẢTS)

Tổng

\begin{tabular}{|c|c|}
\hline 4 & 10.5 \\
\hline 34 & 89.5 \\
\hline 38 & 100.0 \\
\hline
\end{tabular}

Nhận xét: Phương pháp phẫu thuật chủ yễu cho nhóm bệnh nhân nghiên cứu là nội soi hỗ trợ (VATS)

Bảng 6: Tôn thương trong mổ

\begin{tabular}{|c|c|c|}
\hline $\begin{array}{c}\text { Đặc điếm tốn thương } \\
\text { trong mổ }\end{array}$ & $\begin{array}{l}\text { Tân } \\
\text { số }\end{array}$ & $\begin{array}{l}\text { Tỷ lệ } \\
\text { \% }\end{array}$ \\
\hline \multirow{9}{*}{$\begin{array}{c}\text { Bóng đơn độc thùy trên } \\
\text { Bóng kén rải rác } \\
\text { Chùm bóng kén thùy trên } \\
\text { Phổi dính, bóng đơn độc thùy trên } \\
\text { Phổi dính, bóng kén rải rác } \\
\text { Phổi dính, bóng kén thùy trên, } \\
\text { máu cục màng phổi } \\
\text { Phổi dính, chùm bóng kén thùy trên } \\
\text { Phổi dính, rò khí nhu mô } \\
\text { Tổng }\end{array}$} & 2 & 5.3 \\
\hline & 10 & 26,4 \\
\hline & 7 & 18.4 \\
\hline & 6 & 15.8 \\
\hline & 5 & 13.2 \\
\hline & 4 & 10.5 \\
\hline & 7 & 18.4 \\
\hline & 2 & 5.3 \\
\hline & 38 & 100.0 \\
\hline
\end{tabular}

Nhận xét: Chỉ có $60,52 \%$ trường hợp phát hiện bóng kén khí trên CLVT lồng ngực nhưng thực tế trong quá trình phẫu thuật, tỳ lệ phát hiện bóng kén khí cao hơn rất nhiều 94,74\%

Bảng 7: Tỷ lệ gây dính màng phổi

\begin{tabular}{|c|c|c|}
\hline Tỷ lệ gây dính màng phổi & Tân số & Tỷ lệ \% \\
\hline \multirow{2}{*}{$\begin{array}{c}\text { Có } \\
\text { Không } \\
\text { Tổng }\end{array}$} & 21 & 55.3 \\
\cline { 2 - 3 } & 17 & 44.7 \\
\cline { 2 - 3 } & 38 & 100.0 \\
\hline
\end{tabular}

Nhận xét: Tỷ lệ bệnh nhân được gây dính màng phổi và không được gây dính màng phổi là tương đương nhau, điều này cho thây quan điểm về gây dính màng phổi chưa thực sự thống nhất

- Thời gian phẩu thuật trung bình là $62,5 \pm$ 18,33 phút. Thời gian ngắn nhất là 35 phút, dài nhất là 90 phút

- Thời gian nằm hậu phẫu trung bình là 4,47 $\pm 1,11$. Thời gian ngắn nhất là 2 ngày, thời gian dài nhất là 7 ngày

- Thời gian nằm viện trung bình là $5,74 \pm$ 0,92 . Thời gian nằm viện ngắn nhất là 4 ngày, dài nhất là 8 ngày

- Tai biến: không có trường hợp nào xảy ra tai biến hoặc tử vong

- Tái phát: theo dõi sau phẫu thuật tính đến
04/2021, chưa có trường hợp nào tái phát

\section{BÀN LUÂN}

Tràn khí màng phổi tự phát tiên phát cho đến nay vẫn còn là vấn đề toàn cầu do tỷ lệ mắc thường cao, chi phí điều trị lớn, diễn biến thường đột ngột ở bệnh nhân khỏe mạnh... Mặt khác, tỷ lệ tái phát sau can thiệp chọc hút, dẫn lưu màng phổi vẫn chiếm một tỳ lệ nhất định. Qua nghiên cứu chúng tôi ghi nhận một số kết quả như sau:

Đặc điểm chung: Giới tính: trong 38 bệnh nhân được nghiên cứu, nam giới 30/38 chiếm tới $78,95 \%$, tỷ lệ nam/nữ là 3,75/1. Theo nghiên cứu của Ayed A.K và cộng sự ${ }^{4}$ trong 208 bệnh nhân nam giới chiếm 95\%. Tuổi: Nhóm 20-40 tuổi hay gặp hơn cả chiếm 42,11\%. Vì ít có bệnh lý phổi sằn có, cũng như những bệnh lý khác đi kèm. Al-Tarshihi M.I ${ }^{5}$ nhận thấy tuổi nghiên cứu từ 16 - 37 tuổi. Chúng tôi ghi nhận tràn khí tái phát cùng bên là chủ yếu $(64,7 \%)$ và sự tái phát này xảy ra nhiều ở nhóm can thiệp chọc hút, dẫn lưu KMP. Như vậy có thể khẳng định lại chọc hút hay dẫn lưu là điều trị bảo tồn, chưa triệt để trong đó các tổn thương bóng, kén khí vẫn chưa được giải quyết.

Lâm sàng và cận lâm sàng: Lâm sàng: Triêuu chứng tức ngực có ở tất cả các bệnh nhân, triệu chứng kèm theo được chúng tôi ghi nhận bao gồm $21,1 \%$ ho và $39,5 \%$ khó thở với mức độ khó thở ít đến trung bình. Theo Shih $\mathrm{C} . \mathrm{H}^{6}$ và cộng sự nghiên cứu 78 bệnh nhân cho thấy triệu chứng đau ngực chiếm $88,5 \%$, đau xuất hiện đột ngột nhất ở sau vai khi thay đổi tư thế hoặc hít sâu. Tuy nhiên, triệu chứng đau cũng có thể giảm dần rồi hết hẳn sau $2-3$ ngày dù không điều trị gì. Có nhiều bệnh nhân chịu đựng vài ngày mới tìm đến thầy thuốc, vì triệu chứng không rõ rệt nên dễ bỏ qua do nghĩ tới nguyên nhân thông thường khác. Cận lâm sàng: Chụp Xquang ngực rất có giá trị xác định TKMP. Theo cách đánh giá mức khí trên phim X-quang ngực của BTS $(2003)^{1}$. Trong nghiên cứu của chúng tôi có $57,89 \%$ tràn khí nhiều; $13,16 \%$ ở mức trung bình và $28,95 \%$ ở mức ít; $52,6 \%$ TKMP bên phải; $44,7 \%$ bên trái và 1 trường hợp (2,6\%) TKMP 2 bên (Bảng 1). Có 4 trường hợp 
tràn khí tràn máu màng phổi chiếm 10,53\% (Bảng 6). Tương tự các nghiên cứu khác như Lê Quốc Việt và Nguyễn Công Minh ${ }^{7}$, cho biết 6/21 trường hợp tràn khí nhiều và toàn bộ, $5 / 21$ trường hợp mức khí 20 - 40\%, không trường hợp nào mức khí dưới $20 \%$

Phẫu thuật và điều trị: Phương pháp phẫu thuật: Hầu hểt chúng tôi tiến hành phẫu thuật nôi soi hai lỗ vào (biportal) chiếm 89,5\% (Bảng 5) với trocar cho ống kính nội soi tại khoang liên sườn VII đường nách giữa và một vết rạch khoảng $3-5 \mathrm{~cm}$ tại vị trí dẩn lưu KMP cũ ở khoang liên sườn $\mathrm{V}$ đường nách giữa. Có $4 / 38$ trường hợp tràn khí tràn máu do kén khí võ kèm theo tổn thương đứt mạch máu nằm trong tổ chức dính nhu mô vào thành ngực gây chảy máu, trong đó 1 trường hợp đã được truyền máu ở tuyến trước và khi vào khoa được truyền máu, mổ cấp cứu (Bảng 6). Do tràn khí kèm theo, phổi không nở được nên ít có khả năng tự cầm máu, lượng máu KMP tăng, trong trường hợp nặng bệnh nhân có thể trụy mạch và tử vong. Tỷ lệ tràn khí tràn máu cũng được ghi nhận trong một số nghiên cứu trên thế giới. Các tác giả có đều nhận thấy toàn trạng bệnh nhân nặng, cần can thiệp phẫu thuật sớm. Nghiên cứu của Ohno $\mathrm{K}$. và cộng sự: ghi nhận trong 424 bệnh nhân TKMP tự phát nguyên phát có 9 bệnh nhân tràn khí tràn máu và được phẫu thuật cấp cứu. Các tác giả cho rằng: tràn khí tràn máu màng phổi tự phát do võ bóng khí màng phổi dính vào thành ngực vùng đỉnh võ làm tổn thương đứt mạch gây chảy máu lớn, đe dọa tử vong, cần can thiệp sớm. Tỳ lệ chuyển mổ mở: không có trường hợp nào trong nghiên cứu của chúng tôi phải chuyển mổ mở. Tham khảo nghiên cứu của Cardillo và cộng sự (2000) ${ }^{9}$ trong 432 trường hợp có 2 trường hợp chuyển mổ mở do rò khí không xử trí được ở cuối cuộc mổ nội soi. Gây dính màng phổi: 21 trường hợp được gây dính màng phổi sau khi xử trí bóng kén khí bằng cách đốt màng phổi thành vùng đỉnh hoặc trà sát bằng tăm pông và bơm $10 \mathrm{ml}$ Betadine $10 \%$ vào $\mathrm{KMP}$ (Bảng 7). Còn 17 trường hợp không gây dính. Gây dính phòng tái phát còn có những ý kiến trái ngược nhau. Như trong nghiên cứu của Lê Quốc Việt và Nguyễn Công Minh ${ }^{7}$ nghiên cứu trên 21 trường hợp khâu kén khí đơn thuần mà không gây dính màng phổi, kết quả rất tốt, theo dõi tối đa 29 tháng, không trường hợp nào tái phát. Thời gian phấu thuật trung bình của chúng tôi là $62,5 \pm 18,33$ phút (35-90) chủ yếu thực hiện bằng phương pháp VATS (bảng 5). Tương tự nghiên cứu của Cheng Y.J và cộng sự ${ }^{10}$ cũng thực hiện cắt bóng khí và gây dính cơ học, thời gian phẫu thuật $45,6 \pm 18,3$ phút $(25-96)$. Thời gian hậu phẫu trung bình của chúng tôi là $4,47 \pm 1,11$ ngày $(2-7)$. Kết quả này cũng tương tự trong các nghiên cứu khác như Cheng Y.J và cộng sự10 có thời gian hậu phẫu trung bình $4,4 \pm 2,5$ ngày. Thời gian nằm viện trung bình của chúng tôi là $5,74 \pm 0,92$ (4-8) tương tự với một số nghiên cứu khác. Cụ thể: Lê Quốc Việt \& $\mathrm{CS}^{3}$ là $5,92 \pm 0,47$. Tai biến: không có trường hợp nào tai biến hoặc tử vong. Tái phát: theo dõi sau phẫu thuật tính đến 04/2021, chưa có trường hợp nào tái phát. Kết quả này rất đáng khích lệ, cho thấy hiệu quả và ưu điểm của phương pháp điều trị này

\section{KẾT LUÂN}

Phẫu thuật nội soi lồng ngực là phương pháp an toàn, hiệu quả trong điều trị tràn khí màng phổi tự phát tiên phát. Phương pháp này mang lại nhiều ưu điểm cho người bệnh như tính thẩm mỹ, ít đau sau mổ, thời gian nẳm viện ngắn.

\section{TÀI LIỆU THAM KHẢO}

1. Henry M., Arnold T., Harvey J., on behalf of the BTS pleural Disease Groupe off the BTS Standards of Care Committee (2003), "BTS guiderlines for the management of spontaneous pneumothorax". Thorax, 58, (Suppl II), ii39 - ii52

2. Casadio, C., et al. (2001), Primary spontaneous pneumothorax. Is video-assisted thoracoscopy stapler resection with pleural abrasion the goldstandard? European Journal of Cardio-Thoracic Surgery, 20(4): p. 897-898.

3. Lê Quốc Viêt, Nguyển Công Minh - đánh giá hiệu quả điêu trị TKMP tự phát nguyên phát bằng DĹMP và NSLN, tap chí Y Hoc TP. Hồ Chí Minh, Tập 15, Phụ bản của Số 4, 2011

4. Ayed, A.K., C. Chandrasekaran, and $M$. Sukumar (2006), Video-assisted thoracoscopic surgery for primary spontaneous pneumothorax: clinicopathological correlation. European Journal of Cardio-Thoracic Surgery, 29(2): p. 221- 225.

5. Al-Tarshihi M. I., (2008), "Comparison of the efficacy and safety of video-assisted thoracoscopic surgery with the open method for the treatment of primary pneumothorax in adults". Ann Thorac Med, 3(1), p.9-12.

6. Shih C.H., Yu H.W., Tseng Y.C., Chang Y.T. Liu C.M., Hsu J.W., (2011), "Clinical manifestations of primary spontaneous pneumothorax in pediatric patients: an analysis of 78 patients". Pediatr Neonatol, 52(3), p.150-4.

7. Lê Quốc Viêtt, Nguyến Công Minh - Nghiên cứu đánh giá hiểu chống tái phát TKMP nguyên phát bằng PTNSLǸ, tạp chí Y Hoc TP. Hồ Chí Minh, Tập 15, Phụ bản của Số 1, 2011

8. Ohno K., Miyoshi S., Minami M., Akashi A., Maeda H., Nakagawa K., Matsumura A. Nakamura K., Matsuda H., Ohashi S., (2000), "Ipsilateral recurrence frequency after videoassisted thoracoscopic surgery for primary 
spontaneous pneumothorax.". Jpn J Thorac Cardiovasc Surg., 48(12), p.757-60.

9. Cardillo G (2000): Videothoracoscopic treatment of primary spontaneous pneumothorax: a 6- year experience. Ann Thorac Surg; 69:357-361.
10. Cheng Y.J., Kao E.L., Lee J.Y., (2007), "Retrospective comparison of needle thoracoscopy and conventional thoracoscopic surgery to treat primary spontaneous pneumothorax". Surg Laparosc Endosc Percutan Tech, 17(2), p.104-6.

\section{CẢM NHÂ̂N CỦA KHÁCH HÀNG VỀ CHẤT LƯỢNG DİCH VỤ TIÊM NộI NHÃN ĐIỀU TRI MộT SỐ BỆNH MACH MÁU VÕNG MẠC TẠI BỆNH VIỆN MẮT TRUNG ƯƠNG NĂM 2020}

\section{TÓM TẮT.}

Mục tiêu: Chất lượng dịch vụ có vai trò quan trong, là một trong những nhân tố quyêt định sự tồn tại, thành công cũng như góp phần xây dựng uy tín, hình ảnh thương hiệu của tổ chức. nghiên cứu của chúng tôi được thực hiện nhằm mục tiêu mô tả cảm nhận của khách hàng về chất lượng dịch vụ tiêm nội nhã̃n điều trị môtt số bênh mạch máu võng mạc và phân tích một sổ yếu tổ ảnh hưởng tại BV Mắt Trung ương năm 2020. Phương pháp: Nghiên cứu mô tả cắt ngang, kết hợp nghiên cứu định lượng và nghiên cứu đinh tính. Nghiên cứu được thức hiện tai Bênh viện Mắt Trung ương từ tháng 10/2019 đến đến tháng 02/2020. Mẫu nghiền cứu gồm 88 khách hàng đã sứ dụng dịch vụ tiêm nội nhãn. Chất lượng dịch vụ được đánh giá bằng thang đo SERVPERF. Kêt quả: Điếm đánh giá trung bình đạt $4.24 \pm 0.041$ trên trên thang đo Likert có giá trị tối đa 5 điểm. Khía canh sư đảm bảo đạt điểm cao nhất trong các cấu phần (điểm trung bình 4.45), điểm trung bình các khía canh tin cậy, hữu hình, đáp ứng, cảm thông lần lượt là 4.36; $4.16 ; 4.12$ và 4.10 điểm. Kết luận: Kết quả nghiên cứu cho thấy người bệnh đánh giá tốt chất lượng dịch vụ tiêm nội nhãn do Bệnh viện Mắt Trung Ương cung cẩp. Bệnh viên cần tiếp tục duy trì các biện pháp tăng cường chất lượng dịch vụ nhãn

Từ khóa: Chất lượng dịch vụ, SERVPERF, tiêm nội

\section{SUMMARY

\footnotetext{
${ }^{1}$ Bệnh viện Mắt Trung Ương

${ }^{2}$ Trường Đại học Y tế công cộng

Chịu trách nhiệm chính: Đặng Trân Đạt

Email: dangtrandat.vnio@gmail.com

Ngày nhận bài: 4.5.2021

Ngày phản biện khoa học: 25.6.2021

Ngày duyệt bài: 6.7.2021
}

ASSESSMENT OF CLIENTS PERCEPTION ON QUALITY OF SERVICES FOR INTRAVITREAL INJECTION AT VIETNAM NATIONAL INSTITUTE OF OPHTHALMOLOGY IN 2019

Objective: Service quality is one of the determining factors in the success of any hospital, enhancing not only the reputation and brand image but also the competitiveness of the hospital, all of

\section{Đặng Trần Đạt ${ }^{1}$, Vũ Thị Hoàng Lan²}

which contributes largely to attracting and retaining customers, as well as improving satisfaction. This study aims to assess the perception of clients who use the intravitreal injection and analyze several factors influencing the quality of this service at Vietnam National Institute of Ophthalmology in 2019. Methods: Descriptive cross-sectional study combined with qualitative research. Sample included 88 clients used intravitreal injection services at VNIO during $10 / 2019$ to 2/2020. Quality of services were assessed using SERVPERF model with 5 components of service quality. Results: The result for customer perception on the quality of intravitreal injection service in VNIO on SERVPERF scale reached $4.24 \pm 0.041$ points. Customer perception is highest in terms of Assurance with 4.45 points while aspects of Reliability, Tangible, Response, Empathy gain an average score of 4.36 ; $4.16 ; 4.12 ; 4.10$ points respectively. Conclusions: Overall, client's perception of quality of intravitreal injection services in VNIO was good. VNIO need to continue maintain and improve this service quality.

Keywords: quality services, SERVPERF, intravitreal injection

\section{I. ĐẶT VẤN ĐỀ}

Chất lượng dịch vụ có vai trò quan trong, là một trong những nhân tố quyết định sự tồn tại, thành công cũng như góp phân xây dựng uy tín, hình ảnh thương hiệu của tổ chức. Trong nghiên cứu của Cronnin và Taylor được tiến hành vào năm 1992 đã đề xuất mô hình SERVPERF đo lường chất lượng cung cấp dịch vụ. Theo Cronnin và Taylor thì "Chất lượng dịch vụ có thể được đo lường tốt nhất bởi kết quả của quá trình cung cấp dịch vụ được cảm nhận bởi khách hàng". Chất lượng dịch vụ được cảm nhận bởi khách hàng là một kiểu thái độ, một sự đánh giá mang tính lâu dài của khách hàng về chất lượng dịch vụ; trong khi đó sự hài lòng khách hàng về chất lượng dịch vụ là khái niệm liên quan đến việc đo lường một sự chuyển giao dịch vụ cụ thể[1,2].

Các bệnh lý mạch máu võng mạc như thoái hóa hoàng điểm tuổi già, bệnh võng mạc do đái tháo đường, tắc tĩnh mạch võng mạc là một trong các nguyên nhân hàng đâu đe dọa mất thị 